\title{
Surgical outcome and graded prognostic assessment of patients with brain metastasis from adult sarcoma: Multi-institutional retrospective study in Japan
}

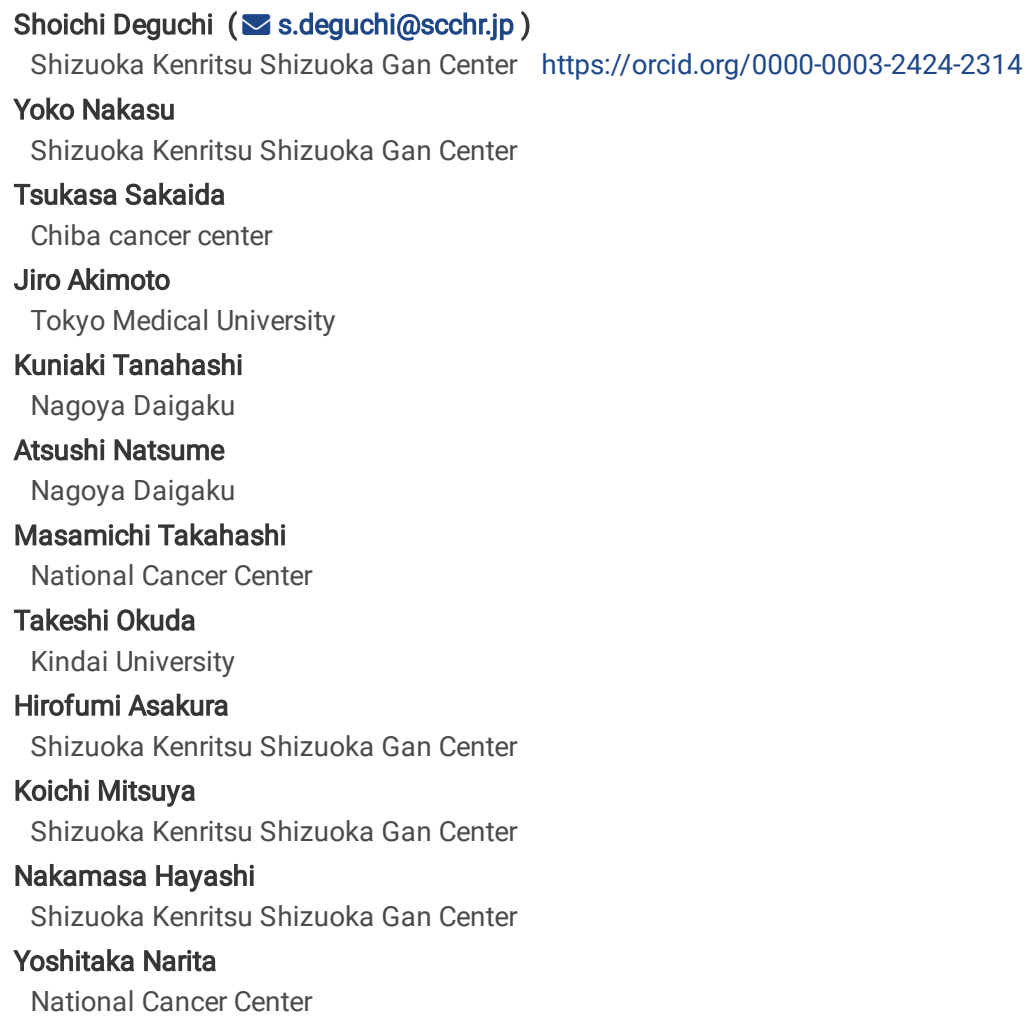

Version of Record: A version of this preprint was published at International Journal of Clinical Oncology on July 9th, 2020. See the published version at https://doi.org/10.1007/s10147-020-01740-8. 


\section{Abstract}

Background: Little information is available about the feasibility and prognostic assessment of surgical resection of brain metastasis (BM) from sarcomas. We aimed to analyze functional and survival outcomes, and develop a preoperative graded prognostic assessment (GPA) for patients with BM from sarcomas to predict survival time after local resection surgery. Methods: This study involved a multi-institutional retrospective analysis of 22 patients with BM from sarcomas who underwent resection at six institutes in Japan between September 2002 and September 2018.0verall survival (OS) after resection of BM was calculated by the Kaplan-Meier method. Prognostic factors were analyzed to develop a GPA using the log-rank test and Cox regression analysis. $\mathrm{P}<0.05$ was considered to indicate statistical significance. For GPA validation, we collected data on 100 patients from 48 published reports. Results: Postoperative Karnofsky Performance Status (KPS) was improved in 50\% (11/22) of patients. Median OS was 21 months. Univariate analysis of OS showed that age ( $\geq 30$ years old), gross total resection, and alveolar soft part sarcoma (ASPS) were significant positive prognostic factors $(P<0.05)$. Multivariate analysis of OS showed age and ASPS were significant preoperative prognostic factors $(P<0.05)$. RTOG-RPA classification had no significant prognostic value. We developed a GPA system for survival time after resection of BM in our patients. A score of 0 was assigned to patients aged 18-29 years with non-ASPS, a score of 2 to patients aged 18-29 years with ASPS or those aged 30-76 years with non-ASPS, and a score of 4 to patients aged 30-76 years with ASPS. Median OS for patients with GPA scores of 0,2 , and 4 were $6.5,16.0$, and 44.0 months, respectively $(P=0.002)$. The results were validated by the survival data of 100 patients compiled from the literature $(P<0.001)$. Conclusion: Patients with $B M$ from sarcomas surgically treated showed median survival comparable to that of patients with BM from carcinomas,and showed improvement in postoperative KPS. We developed a new GPA of patients with BM from sarcomas. These results may help patients and clinicians to select resection as a feasible option for treating BM from sarcomas.

\section{Background}

Adult sarcomas are an uncommon, heterogeneous entity of solid tumors of mesenchymal origin with various distinct histological subtypes, accounting for $1 \%$ of all adult malignancies [1]. Brain metastasis (BM) from sarcomas is also rare, occurring in $1 \%-8 \%$ of sarcoma patients [2,3]. However, the incidence may increase due to advances in irradiation and systemic therapy effective for systemic disease but ineffective for BM [4, 5]. In fact, new systemic agents have shown encouraging activity in patients with advanced sarcomas of certain subtypes [6-9].

Survival outcomes in patients with BM are poor and treatment options are limited [10]. Surgical resection remains an important option for BM treatment. It aims at rapid mass reduction and improvement of neurological status, which may contribute to better performance status in patients with BM [11]. Surgical resection may locally control intracranial lesions, and may also provide opportunities for further systemic therapy and prolong the survival of selected patients with BM from sarcomas.

Surgical candidates should be selected carefully in consideration of the risks of craniotomy [11]. We need a system for assessing the prognosis of individual patients supporting decision-making regarding surgical resection. However, owing to the rarity of sarcomas, there are only a few reports about the feasibility or prognostic factors of surgical resection for BM from sarcomas [10, 12]

Here, we performed a nationwide multi-institutional study to evaluate recent clinical features and surgical outcomes, and constructed a preoperative graded prognostic assessment (GPA) of patients with BM from sarcomas.

\section{Methods}

This study was a multi-institutional retrospective analysis of 22 patients over the age of 18 years with BM from sarcomas who underwent resection at six institutes in Japan between September 2002 and September 2018.

The indication for surgical removal of BM from sarcomas is similar to that for BM from carcinomas, depending on the judgment of neurosurgeons at each institute. We excluded sarcomas directly invading the skull base, hemangiopericytomas, chordomas, and gliosarcomas. The clinical data included date of birth, sex, date of the primary sarcoma diagnosis and presence of BM, histological type, number and maximum size of BMs, side/location of BM, symptoms due to BM, presence of intratumoral hemorrhage, date of surgical resection of BM, extent of resection, pre- and postoperative Karnofsky Performance Status (KPS), presence of lung metastases, whether the primary lesion was controlled at BM diagnosis, type of adjuvant therapy for BM, date of death or last followup visit, and cause of death. Overall survival (OS) was calculated from the date of diagnosis of BM to death from any cause or the last day of follow-up using Kaplan-Meier methods.

For validation study of GPA on surgical resection of brain metastases, we collected published literature about patients with BM from sarcomas who underwent surgical resection [3-5, 13-57]. The National Library of Medicine search engine, PubMed, was utilized for the literature search. For each of the sarcomas, the search terms "brain" and "intracranial" were combined with the tumor's name: "osteosarcoma," "Ewing's sarcoma," "malignant fibrous tumor," "malignant fibrous histiocytoma," "fibrosarcoma," "liposarcoma," "alveolar soft part sarcoma," "chondrosarcoma," "pleomorphic sarcoma," "leiomyosarcoma," "rhabdomyosarcoma," "malignant peripheral nerve sheath tumor," "MPNST," or "angiosarcoma." Relevant articles describing case reports or clinical studies were selected, and the reference lists from these articles were also inspected for other relevant articles [58]. The reports without survival data after craniotomy for BM were excluded. Only publications in English, peer-reviewed journals were included.

Prognostic factors were analyzed using the log-rank test for univariate analysis and Cox regression analysis for multivariate analysis. A P value < 0.05 was considered to indicate statistical significance. Statistical analyses were performed using EZR statistical software [59].

\section{Results}




\section{Patient characteristics}

The characteristics of our 22 patients with BM from sarcomas who underwent surgical resection are shown in Table 1 and summarized in Table 2. Eleven patients were male. The median age at the time of craniotomy was 45 years (range: 18-76). In terms of the histological diagnoses of sarcoma, alveolar soft part sarcoma (ASPS) was the most common (27\%). The median time from diagnosis of the primary sarcoma to the appearance of BM was 20 months (range: 0-267), including two patients with BM prior to the diagnosis of primary sarcomas. Twenty patients (91\%) were symptomatic. Eight patients (36\%) had multiple BMs, and the laterality and location in the brain varied. Although lung metastases had already occurred in 19 patients (86\%) at the time of craniotomy, the primary sarcomas were controlled in six patients (27\%). Intra-tumoral hemorrhage of the BM was detected in seven patients (32\%). Twentyone patients (95\%) underwent complete removal of the brain lesion. Postoperative mortality rate was $0 \%$ within 30 days.

\section{Changes of KPS in perioperative period in our cohort}

Neither pre- nor postoperative KPS was a significant prognostic factor for OS. However, surgical removal markedly improved postoperative KPS in 50\% (11/22) of the patients, especially in patients with lower preoperative KPS (Fig. 1).

Univariate and multivariate analyses of overall survival in our cohort

Fig. 2 presents Kaplan-Meier survival curves for BM from sarcomas. Median OS was 21 months [95\% confidence interval (Cl) 7-30 months]. Univariate analysis of OS showed that age ( $\geq 30$ years old), gross total resection (GTR), and histology of ASPS were significant positive prognostic factors (P<0.05, Table 2A and Fig. 3A, B). Radiation Therapy Oncology Group (RTOG) recursive partitioning analysis (RPA) classification [60-62] had no significant prognostic value in our cohort $(P=0.62$, Fig. $3 C$ ). Number of $B M s$, control of the primary sarcomas, and presence of pulmonary metastases also did not significantly correlate with the OS. Multivariate analysis of OS showed that age ( $\geq 30$ years old) and histological diagnosis of ASPS were significant preoperative prognostic factors $(\mathrm{P}<0.05$, Table $2 \mathrm{~B})$. The hazard ratios of age ( $\geq 30$ years old $)$ and ASPS were 0.16 and 0.11 .

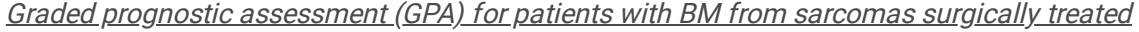

A new GPA index was introduced to predict individual survival after surgical resection of BM from sarcomas, as shown in Table 3. The GPA consisted of age and histology as independent prognostic factors. A score of 0 was assigned to patients aged 18-29 years with non-ASPS sarcomas, a score of 2 to patients aged 18-29 years with ASPS or aged 30-76 years with non-ASPS sarcomas, and finally a score of 4 to patients aged 30-76 years with ASPS. Kaplan-Meier survival curves showed that the median durations of OS for our 22 patients with GPA scores of 0,2 , and 4 were $6.5,16.0$, and 44.0 months, respectively, which were significantly different $(P=0.002$, Fig. $4 \mathrm{~A})$.

\section{Validation of the GPA for cases in the literature}

Data on 100 patients were collected from 48 published reports about patients with BM from sarcomas who underwent surgical resection [3-5, 13-57]. The characteristics are summarized in Supplemental Table. Multivariate analysis of OS showed that histological diagnosis of ASPS was a significant preoperative prognostic factor $(P<0.05$, Table 4$)$ and age ( $\geq 30$ years old) was a strong preoperative prognostic factor ( $P=0.11$, Table 4$)$. We adapted our new $G P A$ system to the 100 patients and found that Kaplan-Meier survival curves showed GPA score 4 (10 patients) median 0S 97 months, GPA score 2 (67 patients) median OS 14.5 months, and GPA score 0 (23 patients) median OS 6.2 months, which were significantly different $(P<0.001, F i g .4 B)$.

\section{Discussion}

We found that the median survival of patients with BM from sarcomas surgically treated was comparable to that from carcinomas [63]. Additionally, postoperative KPS was improved in $50 \%(11 / 22)$ of the patients and postoperative mortality was $0 \%$. Surgical resection remarkably improved KPS and the patients' quality of life (QOL). Despite the large size of the BM, $95 \%$ of the patients underwent complete removal of the lesion, which is compatible with the data in previous reports $[5,12,64]$. These results suggest that BM from sarcomas may have features facilitating its safe and complete removal. When we select surgical removal as a treatment option for patients with BM, we ought to consider local control for not only the survival benefit but also for the immediate improvement of QOL.

Our cohort study revealed a few differences in clinical features between BM from sarcomas and that from carcinomas. Sarcomas occur in younger people than carcinomas do. The median age of the patients in this study was 45 years. Given the risk of surgery, resection may be more suitable for BM from sarcomas than for BM from carcinomas, since young people have fewer systemic complications or frailty. However, older age (30-76 years old) was a positive prognostic factor in both our cohorts and the validation group. This result contradicts that of the patients with BM from carcinomas [62]. We hypothesize on two possible reasons for this discrepancy. One is the selection bias for surgical removal in this retrospective study. Another is that adolescents and young adult patients had more aggressive sarcomas in this heterogeneous patient group. 
We found that a histological diagnosis of ASPS is a significant positive prognostic factor for BM from sarcomas with surgical removal. Sarcomas include a variety of pathological diagnoses. ASPS is an extremely rare sarcoma, which accounts for about $0.5 \%-1 \%$ of soft-tissue sarcomas [65]. However, ASPS is characterized by a high incidence (30\%) of BM [66]. In this study, patients with BM from ASPS showed significantly longer OS than those with BM from other tissue types, which is consistent with previous reports [5, 64].

We developed a new GPA system from the data of multiple institutions in Japan, and validated it with 100 cases from 48 published reports [3-5, 13-57]. This GPA comprised patients' age and primary diagnosis because our study demonstrated only age ( $\geq 30$ years old) and histological diagnosis of ASPS as significant preoperative prognostic factors. This GPA on surgical resection of BM from sarcomas enabled prediction of the postoperative survival. This result may help patients and clinicians to select resection as an option for treating BM from sarcomas.

Grossman et al. reported that the RTOG-RPA classification was applicable to patients who were operated on for BM from sarcomas [12]. However, we demonstrated that none of the constitutive factors of RTOG-RPA (age < 65 years old, preoperative KPS, control of primary lesion, and extracranial metastasis) presented significance as a positive prognostic factor in our cohort. Additionally, Grossman's cohort did not contain patients with ASPS who have a high incidence of BM and significantly longer postoperative OS. Regarding age, $86 \%$ and $88 \%$ of the patients were under 65 years of age in our cohort and the validation group, respectively. Preoperative KPS > 60 was reportedly associated with a good prognosis $[3,5,17]$. However, in our cohort, KPS was dramatically improved by surgical resection, especially in patients with worse preoperative KPS, because impaired KPS often depends on neurological deficits before surgery. In addition, patients usually had extracranial metastasis when BM was detected, as our data and previous reports showed [64,66]. On the other hand, control of the primary lesion was not significantly related to OS in our cohort. This discrepancy with previous reports may have resulted from the small size of the study, various degrees of malignancy, and heterogeneous postoperative treatments [11, 64]. Therefore, we concluded that the RTOG-RPA classification for cancerous BM is not appropriate for patients undergoing surgical removal of BM from sarcomas.

Our study has some limitations. The retrospective nature of this study is associated with potential bias of selection for surgical removal, and this study also has a small sample size because of the rarity of sarcomas with BM. Moreover, we analyzed the results in only sarcoma patients with BM surgically treated. Their pre- and postoperative treatments for BM and systemic sarcomas were heterogeneous and individualized. In addition, various subtypes of sarcomas were included in this study because of the rarity of this entity. These factors may have impacted on study outcomes and may limit the strength of the conclusions drawn here.

\section{Conclusions}

We reported that patients with BM from sarcomas surgically treated showed median survival comparable to that of patients with BM from carcinomas, and showed improvement in postoperative KPS. We developed a new GPA of patients with BM from sarcomas, which comprised age and histology. Its clinical application may help patients and clinicians to predict survival time and select resection as an option for treating BM from sarcomas. We would like to encourage patients, surgeons, and oncologists to assess individualized surgical indications for BM from sarcomas.

\section{Abbreviations}

ASPS: Alveolar soft part sarcoma

BM: Brain metastasis

Cl: Confidence interval

GPA: Graded prognostic assessment

GTR: Gross total resection

KPS: Karnofsky Performance Status

OS: Overall survival

QOL: Quality of life

RPA: Recursive partitioning analysis

RTOG: Radiation Therapy Oncology Group

\section{Declarations}

\section{Ethics approval and consent to participate}

This study was approved by the institutional research ethics board of Shizuoka Cancer Center (T29-36-29-2-3). Given the retrospective nature of this study, specific formal consent was not required.

\section{Consent for publication}


Not applicable.

\section{Availability of data and material}

The datasets used and/or analyzed in the current study are available from the corresponding author on reasonable request.

\section{Competing interests}

The authors declare that they have no competing interests.

\section{Funding}

Not applicable.

\section{Author's contributions}

Study concept and design: SD and YN (Yoko Nakasu); Acquisition of data: TS, JA, KT, AN, MT, TO, HA, KM, NH, and YN (Yoshitaka Narita); Analysis and interpretation of data: SD and YN (Yoko Nakasu); Drafting of the manuscript: SD and YN (Yoko Nakasu); Statistical analysis: SD. All authors read and approved the final manuscript.

Corresponding author

Correspondence to Shoichi Deguchi

\section{Acknowledgements}

Not applicable.

\section{References}

1. Jemal A, Siegel R, Xu J, Ward E. Cancer statistics, 2010. CA Cancer J Clin. 2010;60(5):277-300.

2. Espat NJ, Bilsky M, Lewis JJ, Leung D, Brennan MF. Soft tissue sarcoma brain metastases. Cancer. 2002;94(10):2706-11.

3. Yoshida S, Morii K, Watanabe M, Saito T. Brain metastasis in patients with sarcoma: an analysis of histological subtypes, clinical characteristics, and outcomes. Surg Neurol. 2000;54(2):160-4.

4. Flannery T, Kano H, Niranjan A, Monaco EA, 3rd, Flickinger JC, Kofler J, et al. Gamma knife radiosurgery as a therapeutic strategy for intracranial sarcomatous metastases. Int J Radiat Oncol Biol Phys. 2010;76(2):513-9.

5. Salvati M, D'Elia A, Frati A, Santoro A. Sarcoma metastatic to the brain: a series of 35 cases and considerations from 27 years of experience. J Neurooncol. 2010;98(3):373-7.

6. Tawbi HA, Burgess M, Bolejack V, Van Tine BA, Schuetze SM, Hu J, et al. Pembrolizumab in advanced soft-tissue sarcoma and bone sarcoma (SARC028): a multicentre, two-cohort, single-arm, open-label, phase 2 trial. Lancet Oncol. 2017;18(11):1493-501.

7. D'Angelo SP, Mahoney MR, Van Tine BA, Atkins J, Milhem MM, Jahagirdar BN, et al. Nivolumab with or without ipilimumab treatment for metastatic sarcoma (Alliance A091401): two open-label, non-comparative, randomised, phase 2 trials. Lancet Oncol. 2018;19(3):416-26.

8. van der Graaf WT, Blay JY, Chawla SP, Kim DW, Bui-Nguyen B, Casali PG, et al. Pazopanib for metastatic soft-tissue sarcoma (PALETTE): a randomised, double-blind, placebo-controlled phase 3 trial. Lancet (London, England). 2012;379(9829):1879-86.

9. Schoffski P, Chawla S, Maki RG, Italiano A, Gelderblom H, Choy E, et al. Eribulin versus dacarbazine in previously treated patients with advanced liposarcoma or leiomyosarcoma: a randomised, open-label, multicentre, phase 3 trial. Lancet (London, England). 2016;387(10028):1629-37.

10. Chaigneau L, Patrikidou A, Ray-Coquard I, Valentin T, Linassier C, Bay JO, et al. Brain metastases from adult sarcoma: Prognostic factors and impact of treatment. A retrospective analysis from the French Sarcoma Group (GSF/GETO). Oncologist. 2018;23(8):948-55.

11. Arita H, Narita Y, Miyakita Y, Ohno M, Sumi M, Shibui S. Risk factors for early death after surgery in patients with brain metastases: reevaluation of the indications for and role of surgery. J Neurooncol. 2014;116(1):145-152.

12. Grossman R, Ram Z. Recursive partitioning analysis (RPA) classification predicts survival in patients with brain metastases from sarcoma. World Neurosurg. 2014;82(6):1291-4.

13. Agrawal A, Bajaj N, Maroules M. Synovial sarcoma with intracranial metastasis as the site of reoccurrence. Am J Med Sci. 2017;354(5):523-6. 
14. Akutsu H, Tsuboi K, Sakamoto N, Nose T, Honma S, Jikuya T. Cerebral metastasis from angiosarcoma of the aortic wall: case report. Surg Neurol. 2004;61(1):68-71.

15. Auer IA, Auer RN. Metastatic dermatofibrosarcoma protuberans mimicking meningioma. Clin Neuropathol. 1998;17(4):190-3.

16. Bailey SC, Bailey B, Smith NT, Van Tassel P, Thomas CR, Jr. Brain metastasis from a primary liposarcoma of the digit: case report. Am J Clinical Oncol. 2001;24(1):81-4.

17. Bindal RK, Sawaya RE, Leavens ME, Taylor SH, Guinee VF. Sarcoma metastatic to the brain: results of surgical treatment. Neurosurgery. 1994;35(2):18590; discussion 190-81.

18. Buono LM, Silberschmidt A, Foroozan R, Savino PJ: Metastatic synovial sarcoma to the skull base and orbit. Am J Ophthalmol. 2002;134(5):785-7.

19. Capitini CM, Derdak J, Hughes MS, Love CP, Baird K, Mackall CL, Fry TJ. Unusual sites of extraskeletal metastases of Ewing sarcoma after allogeneic hematopoietic stem cell transplantation. J Pediat Hematol Oncol. 2009;31(2):142-4.

20. Chang JW, Howng SL, Sun ZM, Kuo TH, Duh CC. An unusual intracranial metastasis of osteosarcoma. Kaohsiung J Med Sci. 1994;10(12):700-4.

21. Chua C, Raaj J, Pan S, Farid M, Lee JF, Ho ZC, et al. Brain metastasis in sarcoma: Does metastasectomy or aggressive multi-disciplinary treatment improve survival outcomes. Asia Pac J Clin Oncol. 2016;12(1):e16-22.

22. Daigeler A, Kuhnen C, Hauser J, Goertz O, Tilkorn D, Steinstraesser L, et al. Alveolar soft part sarcoma: clinicopathological findings in a series of 11 cases. World J Surg Oncol. 2008;6:71.

23. De B, Kinnaman MD, Wexler LH, Kramer K, Wolden SL. Central nervous system relapse of rhabdomyosarcoma. Pediat Blood Cancer. 2018;65(1).

24. Erguvan-Onal R, Onal C, Gurlek A, Alkan A, Erkal HS, Mizrak B. Metastatic fibrosarcoma of the brain: transformation from conventional to epithelioid formcase report. Neurologia Medico-chirurgica. 2004;44(9):497-501.

25. Fitzpatrick MO, Tan K, Doyle D. Metastatic liposarcoma of the brain: case report and review of the literature. Brit J Neurosurg. 1999;13(4):411-2.

26. Gupta T, Laskar S, Gujral S, Muckaden MA. Brain metastases in soft tissue sarcomas: case report and literature review. Sarcoma. 2005;9(3-4):147-50.

27. Guraya SS, Prayson RA: Brain metastasis from gastrointestinal clear cell sarcoma. Clin Neuropathol. 2017;36(1):41-5.

28. Hagiwara S, Miyazaki T, Ishikawa N, Nakagawa F, Maruyama R, Akiyama Y. Pyothorax-associated angiosarcoma metastasized to the brain with multiple and progressively expanding hematomas: Case report and literature review. Asian J Neurosurg. 2018;13(3):803-9.

29. Hamamoto T, Kono T, Furuie H, Ueda T, Takeno S, Hirakawa K, et al. Extraskeletal osteosarcoma in the parotid gland: A case report. Auris, Nasus, Larynx. 2018;45(3):644-7.

30. Honeybul S, Ha T. Leiomyosarcoma of the uterus metastatic to the brain: a case report. Arch Gynecol Obstet. 2009;279(3):391-3.

31. Kim DG, Lee SY, Chung SK, Park SK, Chun YK, Chi JG. Brain metastasis from myxofibrosarcoma of the heart. Acta Neurochir (Vienna). 1997;139(1):88-9.

32. Konishi H, Isetani K, Satoh T, Fukuda S, Kodama T, Kashima K. A case of metastatic chondrosarcoma of the stomach. J Gastroenterol. 1994;29(4):495500 .

33. Kumar S, Teasdale E. Metastatic liposarcoma of the brain. Clin Radiol. 2000;55(5):406-8.

34. Lin CT, Ducis K, Tucker S, Tranmer B. Metastatic cardiac angiosarcoma to the lung, spine, and brain: A case report and review of the literature. World Neurosurg. 2017;107:1049.e1049-1049.e1012.

35. Ogose A, Morita T, Hotta T, Kobayashi H, Otsuka H, Hirata Y, et al. Brain metastases in musculoskeletal sarcomas. Jpn J Clin Oncol. 1999;29(5):245-7.

36. Olivi A, Donehower RC, Mann RB, Brem H. Solitary, isolated metastasis from Ewing's sarcoma to the brain: case report. Surg Neurol. 1991;35(3):239-43.

37. Park SK, Yi HJ, Paik SS, Kim YJ, Ko Y, Oh SJ. Metastasizing malignant peripheral nerve sheath tumor initially presenting as intracerebral hemorrhage. Case report and review of the literature. Surg Neurol. 2007;68(1):79-84; discussion 84.

38. Perumall VV, Harun R, Sellamuthu P, Shah MSM. Alveolar soft part sarcoma with brain metastases. Asian J Neurosurg. 2017;12(1):112-5.

39. Przkora R, Vogel P, Ullrich OW, Knuchel R, Jauch KW, Bolder U. Synovial sarcoma--unusual presentation with cerebral hemorrhage. Arch Orthop Traum Surg. 2003;123(7):376-8.

40. Salvati M, Cervoni L, Caruso R, Gagliardi FM, Delfini R. Sarcoma metastatic to the brain: a series of 15 cases. Surg Neurol. 1998;49(4):441-4.

41. Simpson RK, Jr., Bruner JM, Leavens ME. Metastatic Ewing's sarcoma to the brain: case report and review of treatment. Surg Neurol. 1989;31(3):234-8.

42. Sun YP, Wang X, Gao YS, Zhao S, Bai Y. Primary cardiac sarcoma complicated with cerebral infarction and brain metastasis: A case report and literature review. Cancer Biomarkers. 2017;21(1):247-50.

43. Takamiya Y, Toya S, lizaka Y, Otani M, Takenaka N, Imanishi T. Intracranial metastasis of soft tissue fibrosarcoma-case report. Neurologia Medicochirurgica. 1986I26(1):54-7.

44. Tanaka H, Sasayama T, Nishihara M, Arai A, Kawamura A, Kanomata N, et al. Brain metastasis of undifferentiated sarcoma and response to temozolomide treatment. Case report. Neurologia Medico-chirurgica. 2010;50(8):689-93.

45. Tao X, Hou Z, Wu Z, Hao S, Liu B. Brain metastatic alveolar soft-part sarcoma: Clinicopathological profiles, management and outcomes. Oncol Lett. 2017;14(5):5779-84.

46. Tilgner J, Muller K, Ghanem N, Lutterbach J, Vesper J. Brain metastases as primary manifestation of a melanocytic malignant peripheral nerve sheath tumor in a 60-year-old man. BMC Neurol. 2007;7:2.

47. Urakawa H, Tsukushi S, Kozawa E, Ikuta K, Hamada S, Ishiguro N, et al. Postoperative brain metastases in soft tissue sarcomas. Clin Exp Metastasis. 2015;32(4):345-51. 
48. Vaquero J, Martinez R, el Barkani A, Gomez-Angulo JC, Escandon J. Leiomyosarcoma metastatic to the brain with prolonged survival. J Neurosurg Sci. 1989;33(3):291-2.

49. Vaquero J, Martinez R, Coca S, Oya S, Burgos R. Cerebral metastasis from angiosarcoma of the heart. Case report. J Neurosurg. 1990;73(4):633-5.

50. Vital RB, Hamamoto Filho PT, Lima Neto NM, Caldeira Xavier JC, Santos DC, Romero FR, et al. Brain metastasis from cardiac angiosarcoma. Neurol India. 2014;62(4):451-2.

51. Wang M, Li J, Huan L, Meng F, Pang Q. Alveolar soft part sarcoma associated with lung and brain metastases: A case report. Oncol Lett. 2016;12(2):9568.

52. Wang Y, Cui J, Yan X, Jin R, Hong X. Alveolar soft part sarcoma with multiple brain and lung metastases in pregnancy: A case report and literature review. Medicine. 2017;96(46):e8790.

53. Weil RJ, Lonser RR, Quezado MM. CNS manifestations of malignancies: case 2. Skull and brain metastasis from tibial osteosarcoma. J Clin Oncol. 2005;23(18):4226-9.

54. Wronski M, Arbit E, Burt M, Perino G, Galicich JH, Brennan MF. Resection of brain metastases from sarcoma. Ann Surg Oncol. 1995;2(5):392-9.

55. Wu TH, Shih CW, Huang JS, Wang CH, Yeh KY. Unusual hematogenous brain metastasis in malignant fibrous histiocytoma of the maxillary sinus. Int $\mathrm{J}$ Clin Oncol. 2012;17(1):69-74.

56. Yamada S, Yamada SM, Nakaguchi H, Murakami M, Hoya K, Matsuno A. A case of multiple brain metastases of uterine leiomyosarcoma with a literature review. Surg Oncol. 2011;20(4):e127-1.

57. Ziyal IM, Musluman M, Bejjani GK, Tanik C, Turkmen CS, Aydin Y. Cerebral metastasis of a uterine leiomyosarcoma-case report. Neurologia Medicochirurgica. 1999;39(3):238-41.

58. Shweikeh F, Bukavina L, Saeed K, Sarkis R, Suneja A, Sweiss F, et al. Brain metastasis in bone and soft tissue cancers: a review of incidence, interventions, and outcomes. Sarcoma. 2014;475175.

59. Kanda Y. Investigation of the freely available easy-to-use software 'EZR' for medical statistics. Bone Marrow Transplant. 2013;48(3):452-8.

60. Sperduto PW, Berkey B, Gaspar LE, Mehta M, Curran W. A new prognostic index and comparison to three other indices for patients with brain metastases: an analysis of 1,960 patients in the RTOG database. Int J Radiat Oncol Biol Phys. 2008;70(2):510-4.

61. Sperduto PW, Kased N, Roberge D, Xu Z, Shanley R, Luo X, et al. Summary report on the graded prognostic assessment: an accurate and facile diagnosisspecific tool to estimate survival for patients with brain metastases. J Clin Oncol. 2012;30(4):419-25.

62. Sperduto PW, Shanley R, Luo X, Andrews D, Werner-Wasik M, Valicenti R, et al. Secondary analysis of RTOG 9508, a phase 3 randomized trial of wholebrain radiation therapy versus WBRT plus stereotactic radiosurgery in patients with 1-3 brain metastases; poststratified by the graded prognostic assessment (GPA). Int J Radiat Oncol Biol Phys. 2014;90(3):526-31.

63. Kavouridis VK, Harary M, Hulsbergen AFC, Lo YT, Reardon DA, Aizer AA, et al. Survival and prognostic factors in surgically treated brain metastases. J Neurooncol. 2019;143(2):359-67.

64. Fox BD, Patel A, Suki D, Rao G. Surgical management of metastatic sarcoma to the brain. J Neurosurg. 2009;110(1):181-6.

65. Portera CA, Jr., Ho V, Patel SR, Hunt KK, Feig BW, Respondek PM, et al. Alveolar soft part sarcoma: clinical course and patterns of metastasis in 70 patients treated at a single institution. Cancer. 2001;91(3):585-91.

66. Chou YS, Liu CY, Chen WM, Chen TH, Chen PC, Wu HT, et al. Brain, the last fortress of sarcoma: similar dismal outcome but discrepancy of timing of brain metastasis in bone and soft tissue sarcoma. J Surg Oncol. 2011;104(7):765-70.

\section{Tables}

Table 1 Characteristics of 22 patients with brain metastasis (BM) from sarcoma who underwent surgical resection 


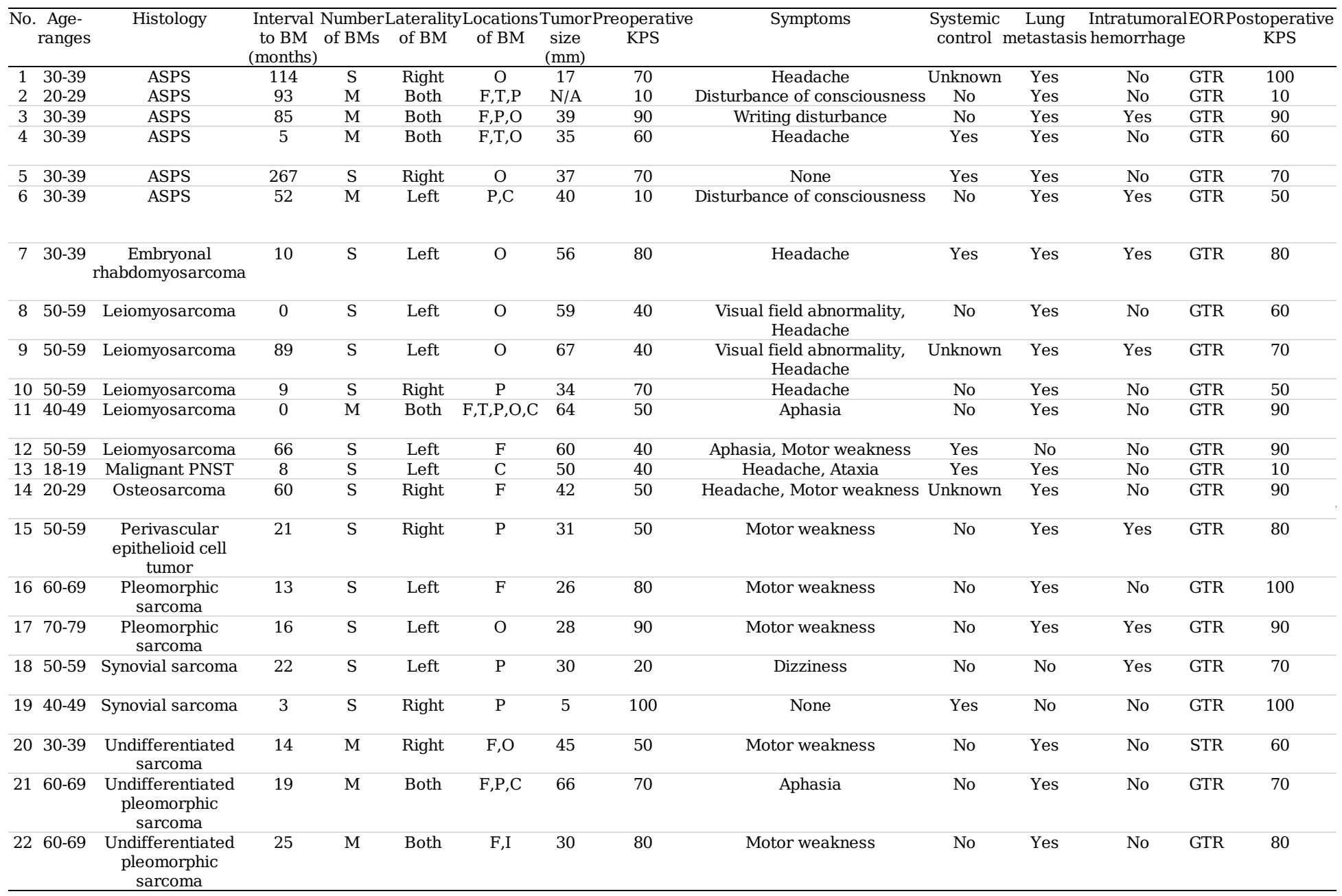

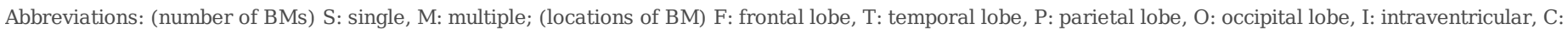

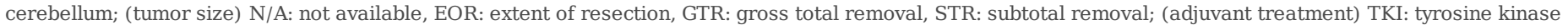
inhibitor, STI: stereotactic irradiation, WBRT: whole-brain radiotherapy, CNS: central nervous system

Table 2A Univariate analysis of overall survival in our cohort 


\begin{tabular}{|c|c|c|c|}
\hline & Number & Median OS & $\mathrm{P}$ value \\
\hline Age & & & 0.003 \\
\hline 18-29 у.о. & 3 & 3 & \\
\hline 30-76 у.о. & 19 & 29 & \\
\hline Sex & & & 0.50 \\
\hline Male & 11 & 21 & \\
\hline Female & 11 & 14 & \\
\hline Number of BMs & & & 0.94 \\
\hline Single & 14 & 16 & \\
\hline Multiple & 8 & 21 & \\
\hline Intratumoral hemorrhage & & & 0.99 \\
\hline Present & 7 & 29 & \\
\hline Absent & 15 & 16 & \\
\hline Systemic control & & & 0.86 \\
\hline Yes & 6 & 16 & \\
\hline No & 13 & 21 & \\
\hline Unknown & 3 & 14 & \\
\hline Lung metastases & & & 0.95 \\
\hline Present & 19 & 21 & \\
\hline Absent & 3 & 16 & \\
\hline Preoperative KPS & & & 0.47 \\
\hline$\geq 70$ & 10 & 30 & \\
\hline$\leq 60$ & 12 & 14 & \\
\hline Postoperative KPS & & & 0.43 \\
\hline$\geq 70$ & 15 & 21 & \\
\hline$\leq 60$ & 7 & 3 & \\
\hline Change of perioperative KPS & & & 0.54 \\
\hline Increase & 11 & 21 & \\
\hline No change or decrease & 11 & 16 & \\
\hline RPA class & & & 0.62 \\
\hline 1 & 1 & 16 & \\
\hline 2 & 9 & 44 & \\
\hline 3 & 12 & 14 & \\
\hline Postoperative chemotherapy & & & 0.74 \\
\hline Yes & 8 & 16 & \\
\hline No & 14 & 29 & \\
\hline Extent of resection & & & 0.002 \\
\hline GTR & 21 & 21 & \\
\hline STR & 1 & 2 & \\
\hline Histology & & & 0.02 \\
\hline ASPS & 6 & 44 & \\
\hline Non-ASPS & 16 & 14 & \\
\hline
\end{tabular}

Abbreviations: OS: overall survival, KPS: Karnofsky Performance Status, GTR: gross total resection, STR: subtotal resection, ASPS: alveolar soft part sarcoma

Table 2B Multivariate analysis of overall survival in our cohort

\begin{tabular}{l|c|c|c}
\hline & Hazard ratio & $95 \square \mathrm{CI}$ & P value \\
\hline Age: $30-76$ & 0.16 & $0.033-0.73$ & $\mathbf{0 . 0 2}$ \\
\hline ASPS & 0.11 & $0.013-0.92$ & $\mathbf{0 . 0 4 6}$ \\
\hline Gender: Men & 1.04 & $0.31-3.51$ & 0.95 \\
\hline
\end{tabular}

Abbreviation: ASPS: alveolar soft part sarcoma

Table 3 Graded prognostic assessment on surgical resection of brain metastasis from sarcoma

\begin{tabular}{l|c|c}
\hline \multirow{2}{*}{} & \multicolumn{2}{c}{ Score } \\
\cline { 3 - 3 } \multicolumn{1}{c|}{} & 0 & 2.0 \\
\hline Age & $18-29$ y.o. & $30-76$ y.o \\
\hline Histological type & Non-ASPS & ASPS \\
\hline
\end{tabular}

Page 9/12 
Table 4 Multivariate analysis of overall survival in validation group

\begin{tabular}{l|c|c|c}
\hline & Hazard ratio & $95 \llbracket C I$ & P value \\
\hline Age: $30-76$ & 0.65 & $0.38-1.11$ & 0.11 \\
\hline ASPS & 0.14 & $0.050-0.39$ & $<0.001$ \\
\hline Gender: Men & 1.05 & $0.64-1.75$ & 0.84 \\
\hline
\end{tabular}

Abbreviations: 95匹 CI: 95\% confidence interval, ASPS: alveolar soft part sarcoma

\section{Figures}

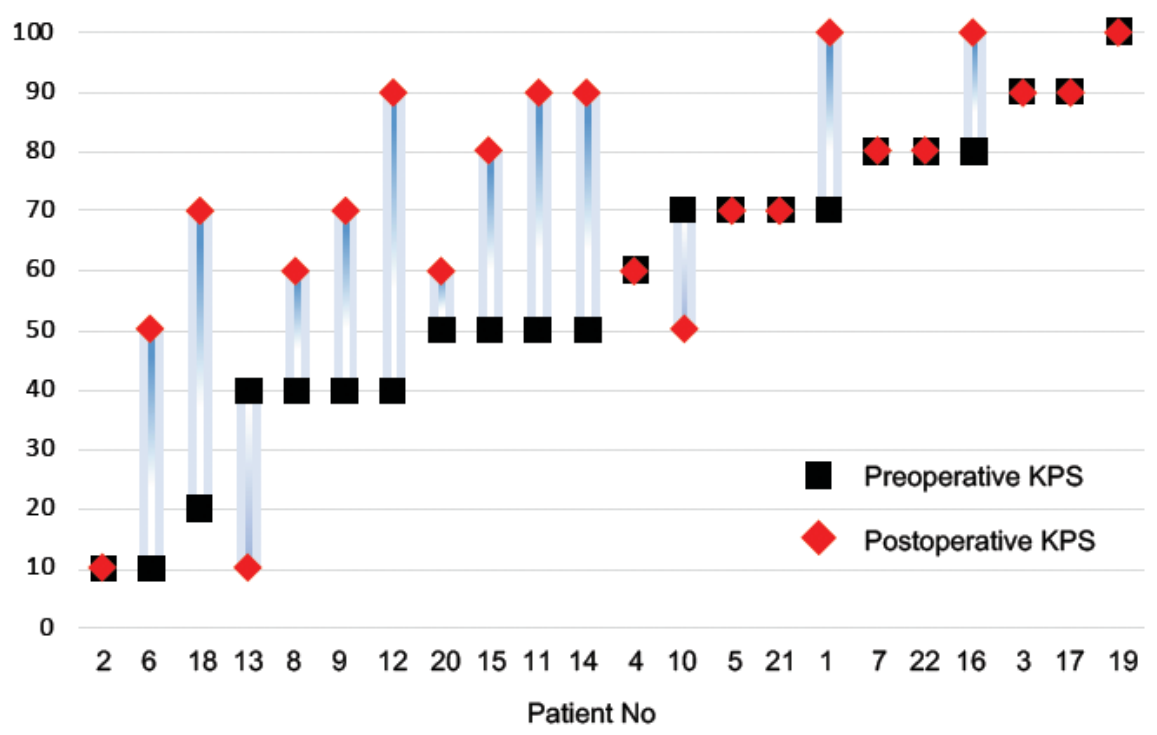

\section{Figure 1}

Individual changes in pre- and postoperative KPS in our cohort. The x-axis represents patient number and the $y$-axis represents the post-and preoperative KPS. Black squares show preoperative KPS and red diamond shapes show postoperative KPS. Note that KPS improved in 11 patients after surgical resection.

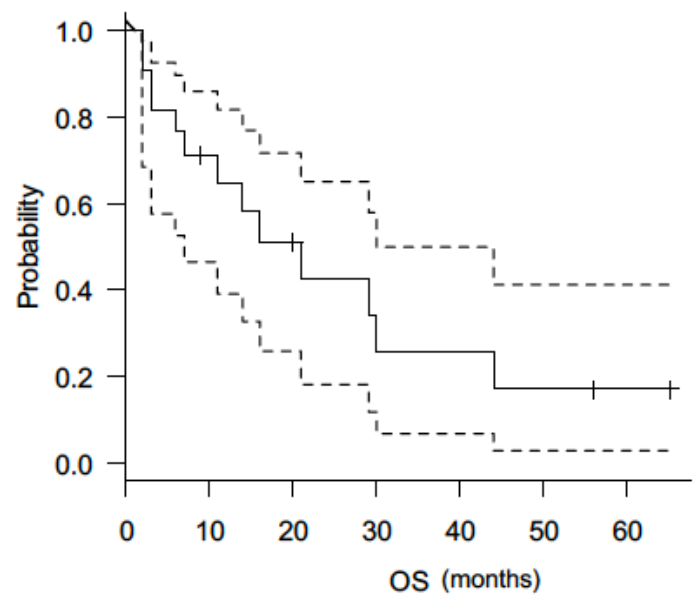

Figure 2

Kaplan-Meier curves of overall survival after surgical resection of BM from sarcomas. Solid line and dotted lines illustrate survival curve and $95 \%$ confidence interval, respectively. Median OS was 21 months. 
Fig.3A

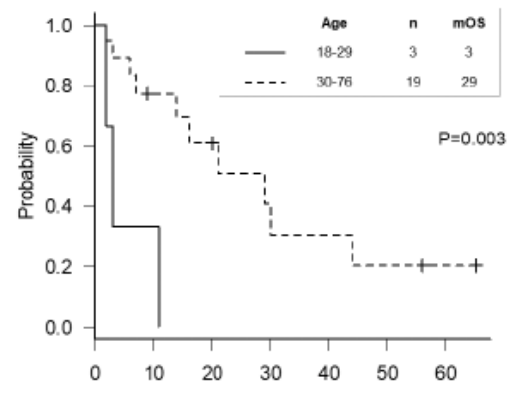

B
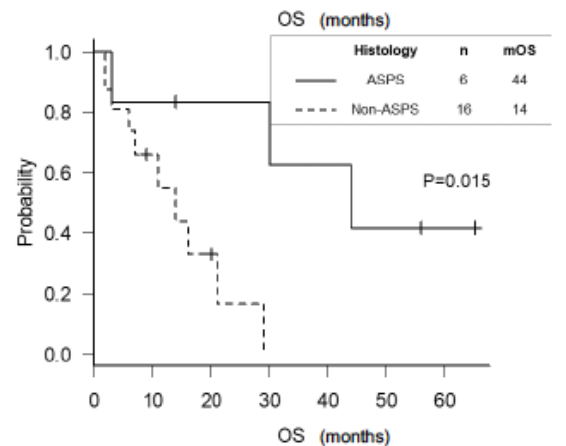

C

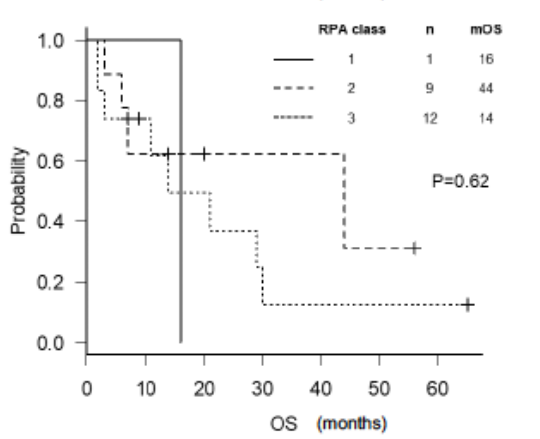

\section{Figure 3}

Kaplan-Meier curves of overall survival. (A) Kaplan-Meier curves of overall survival after surgical resection of BM from sarcomas comparing younger patients aged 18-29 years old (solid line) with older patients aged 30-76 years old (dashed line). (B) Kaplan-Meier curves of overall survival after surgical resection of BM from sarcomas comparing patients with ASPS (solid line) and with non-ASPS (dashed line). (C) Kaplan-Meier curves of overall survival after surgical resection of BM from sarcomas comparing patients with RPA class 1 (solid line), RPA class 2 (dashed line), and RPA class 3 (dotted line). 


\section{Fig.4A}
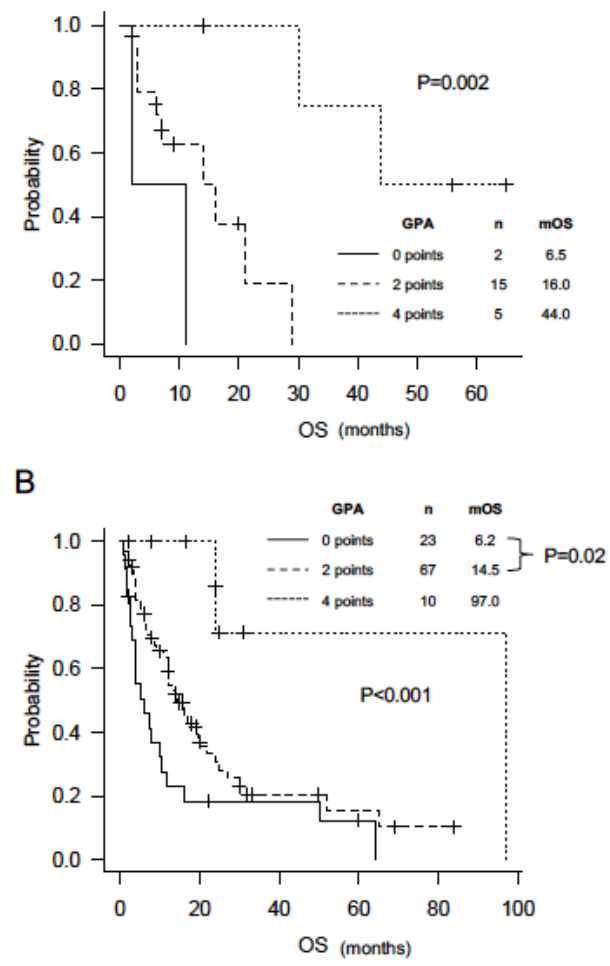

\section{Figure 4}

Kaplan-Meier curves of overall survival after surgical resection of BM from sarcomas according to GPA. (A) our cohort, (B) the validation group 0 points (solid line), 2 points (dashed line), and 4 points (dotted line) 